\title{
Energy Conservation of the Designated Government Buildings in Thailand
}

\author{
Prapat Wangskarn ${ }^{1}$, Monchai Prukvilailert ${ }^{1}$ \\ 1 Thammasat University, Thailand
}

\begin{abstract}
The designated government buildings have implemented and administered energy program under the energy development and promotion Act 2007 for many years continuously until 2015. Appointment person responsible for energy, performing energy management and implementing the energy conservation work plan and measures are legal requirements for the designated buildings. Therefore, the ministry of Energy has launched the project to support the implementation of energy management. The aim of the project was to create the energy management system in the designated government buildings, and to reduce energy consumption. In this paper, the evaluation of the project has been presented from the achievements of 839 designated government buildings. The energy saving is more than $440 \mathrm{ktoe} / \mathrm{year}$. This is about $3 \%$ of energy consumptions of buildings.
\end{abstract}

\section{Introduction}

The Strategic Energy has set a goal of national energy conservation with the aim to reduce at least $25 \%$ of energy consumption per unit of production (Energy Intensity) of manufacturing and services in 2033. By regulatory measures under the Energy Conservation Act 1992, the building sector (about 852 buildings) required to submit reports to Department of Alternative Energy Development and Efficiency (DEDE). However, buildings must arrange a report on the implementation of energy management for inspection and certification by the competent authority before sending the report to DEDE in March of each year. For promoting and overseeing the building sector, DEDE conducted to provide advice in support of the development of an energy management system to ensure compliance with legal requirements and also the event encourages awareness. The working Group on energy management of buildings has been established for preparation of energy management continuously. From the past experience, there is a need to support public sector building steadily. The examination and approval by the competent authorities or inspection and certification of energy management have been prepared.

In fiscal 2015, DEDE send team of consultants to carry out the inspection and certification of energy management in public buildings on the site to verify the actual plans and performance measures for energy conservation.

The government agency that owns the designated buildings has an order to implement energy management programs according to the energy development and promotion Act 2007 [1] in Thailand. The success of energy conservation promotion for the designated government buildings can induce the owner of the designated buildings of private-sector to implement the energy management program under the law [2]-[4].

In the past, we found that some government agencies of the designated buildings were unable to conduct the energy management system according to the law by the lack of personnel who has knowledge and experience [5], [6]. In order to conform to the law, appointment person responsible for energy, performing energy management and implementing the energy conservation work plan and measures must be executed.

Therefore, the project of promotion and conducting the energy conservation regulation and supervision of designated government buildings was launched continuously in 2015 [7].

The project provided the experts on energy management system according to the law to give guidance for the staff of buildings. The agency of the buildings has been forced to implement the energy conservation activities.

In this paper, evaluation of the project has been presented. The effectiveness of the project was assessed in according with energy management activities, number of persons responsible for energy and the energy savings potential.

\section{Evaluation Procedure}

There were 839 designated government buildings applied to the project. The buildings were categorized into 5 groups according as shown in Table 1. 
Table 1. Number of buildings categorized.

\begin{tabular}{|l|l|l|}
\hline No & \multicolumn{1}{|c|}{ Government agency } & \multicolumn{1}{c|}{ Number } \\
\hline 1 & Office & 392 \\
\hline 2 & Academy & 183 \\
\hline 3 & Hospital & 140 \\
\hline 4 & Electrical & 13 \\
\hline 5 & Other & 111 \\
\hline
\end{tabular}

The buildings were also categorized into 21 groups according to their government agencies (19 ministries, the Prime minister's office and independent public agencies) as shown in Table 2.

Table 2. Number of buildings categorized by the agency

\begin{tabular}{|l|l|l|}
\hline No & \multicolumn{1}{|c|}{ Government agency } & Number \\
\hline 1 & Ministry of Agriculture and Cooperatives & 21 \\
\hline 2 & $\begin{array}{l}\text { Ministry of Information and Communication } \\
\text { Technology }\end{array}$ & 25 \\
\hline 3 & Ministry of Labour & 20 \\
\hline 4 & Ministry of Defence & 165 \\
\hline 5 & Ministry of Finance & 19 \\
\hline 6 & Ministry of Foreign Affairs & 2 \\
\hline 7 & Ministry of Tourism \& sports & 8 \\
\hline 8 & $\begin{array}{l}\text { Ministry of Social Development and Human } \\
\text { Security }\end{array}$ & 2 \\
\hline 9 & Ministry of Transport & 47 \\
\hline 10 & $\begin{array}{l}\text { Ministry of Natural Resources and } \\
\text { Environment }\end{array}$ & 8 \\
\hline 11 & Ministry of Energy & 26 \\
\hline 12 & Ministry of Commerce & 2 \\
\hline 13 & Ministry of Interior & 77 \\
\hline 14 & Ministry of Justice & 7 \\
\hline 15 & Ministry of Culture Thailand & 7 \\
\hline 16 & Ministry of Science and Technology & 21 \\
\hline 17 & Ministry of Education & 171 \\
\hline 18 & Ministry of Public Health & 132 \\
\hline 19 & Ministry of Industry & 12 \\
\hline 20 & The Prime Minister's Office & 13 \\
\hline 21 & Independent public agencies & 54 \\
\hline & & \\
\hline
\end{tabular}

The objects of evaluation include:

1. Status of implementation of requirements according to the law;

2. Potential of energy saving by changing the significant equipments;

3. Energy savings.

The data and information were collected from the final reports of the participated designated buildings, questionnaires and direct interview in 2015. Then, the data collation and analysis was performed to evaluate the outcomes of the project.

\section{Results}

\subsection{Status of implementation of requirements according to the law}

According to the energy conservation Act 2007, the government agency of the designated building must submit the energy conservation work plan and having the person responsible for energy (PRE). The work plans for every buildings have been investigated in details.
The work plan has been written in form of a report. It shows the implementation and results of energy conservation activities of buildings. Eight process of energy management system have to be reported the implementation and evaluation as follows:

1. Designation and energy management committee

2. Evaluation of preliminary status of energy management

3. Energy conservation policy

4. Evaluation of energy conservation potential

5. Determination energy conservation plane and target

6. Implementation and operation.

7. Evaluation by internal audit.

8. Management

In the past few years, some buildings did not implement the work plan due to lack of knowledge. This project, therefore, provided expert persons in the field of energy management system to consult and prepare the work plan for all buildings. For the year 2015, Almost buildings were able to submit the work plans in the given period. However, due to the lack of knowledge and experience, some of work plan of buildings having the error of data and missing the important activities of energy management process were not approved.

The work plan that is completed and fully to be approved, it is necessary to show the contents of activities, results and evaluation for 8 steps of energy management process. Ministry of Education and Ministry of Defense have the most buildings in responsibility about 169 buildings and 163 buildings, respectively. Only few number of work plans of buildings that have not been approved. It can be seen that most of government buildings also want to create a culture of law-abidingness.

The results were shown in Table 3 for the investigation of the work plan for government agencies.

Table 3. The results of investigation the work plan categorized by the agency

\begin{tabular}{|c|c|c|c|}
\hline No & Government agency & approved & $\begin{array}{c}\text { Not } \\
\text { approved }\end{array}$ \\
\hline 1 & $\begin{array}{l}\text { Ministry of Agriculture and } \\
\text { Cooperatives }\end{array}$ & 20 & 1 \\
\hline 2 & $\begin{array}{l}\text { Ministry of Information and } \\
\text { Communication Technology }\end{array}$ & 25 & 0 \\
\hline 3 & Ministry of Labour & 20 & 0 \\
\hline 4 & Ministry of Defence & 163 & 2 \\
\hline 5 & Ministry of Finance & 19 & 0 \\
\hline 6 & Ministry of Foreign Affairs & 2 & 0 \\
\hline 7 & Ministry of Tourism \& sports & 7 & 1 \\
\hline 8 & $\begin{array}{l}\text { Ministry of Social Development } \\
\text { and Human Security }\end{array}$ & 2 & 0 \\
\hline 9 & Ministry of Transport & 46 & 1 \\
\hline 10 & $\begin{array}{l}\text { Ministry of Natural Resources } \\
\text { and Environment }\end{array}$ & 8 & 0 \\
\hline 11 & Ministry of Energy & 26 & 0 \\
\hline 12 & Ministry of Commerce & 2 & 0 \\
\hline 13 & Ministry of Interior & 77 & 0 \\
\hline 14 & Ministry of Justice & 7 & 0 \\
\hline 15 & Ministry of Culture Thailand & 7 & 0 \\
\hline 16 & $\begin{array}{l}\text { Ministry of Science and } \\
\text { Technology }\end{array}$ & 21 & 0 \\
\hline 17 & Ministry of Education & 169 & 2 \\
\hline 18 & Ministry of Public Health & 132 & 0 \\
\hline
\end{tabular}




\begin{tabular}{|l|l|c|c|}
\hline No & \multicolumn{1}{|c|}{ Government agency } & approved & $\begin{array}{c}\text { Not } \\
\text { approved }\end{array}$ \\
\hline 19 & Ministry of Industry & 12 & 0 \\
\hline 20 & The Prime Minister's Office & 12 & 1 \\
\hline 21 & Independent public agencies & 53 & 1 \\
\hline
\end{tabular}

After the project period, from 839 designated buildings, the agencies of 759 designated buildings or more than $90 \%$ of the total number of buildings were able to prepare the completed work plan.

Moreover, more than $80 \%$ of the buildings of agencies have already appointed the person responsible for energy (PRE). It can be seen clearly that the project brought about an increased understanding of the implementation under the energy development and promotion Act. However, about $20 \%$ of designated buildings, the agencies were not able to complete the requirement of the number of PRE.

When checking the status of compliance with the laws of the government building in the status of the appointment of the person for responsible energy (PRE) of building we found that 685 buildings ( $80 \%$ of total number of buildings) can meet the requirements of the law. However, 116 buildings (13\% of total number of buildings) still have not appointed PRE fully following the requirements of the law. Furthermore, 59 buildings have no any PRE. In summary, more than 2,500 PRE has been registered and has been appointed for buildings. The details are summarized below.

Table 4. The Number of person responsible for energy categorized by the agency

\begin{tabular}{|l|l|c|c|}
\hline No & \multicolumn{1}{|c|}{ Government agency } & Completed & $\begin{array}{c}\text { Number } \\
\text { of PRE }\end{array}$ \\
\hline 1 & $\begin{array}{l}\text { Ministry of Agriculture and } \\
\text { Cooperatives }\end{array}$ & 17 & 69 \\
\hline 2 & $\begin{array}{l}\text { Ministry of Information and } \\
\text { Communication Technology }\end{array}$ & 23 & 86 \\
\hline 3 & Ministry of Labour & 19 & 59 \\
\hline 4 & Ministry of Defence & 108 & 492 \\
\hline 5 & Ministry of Finance & 19 & 87 \\
\hline 6 & Ministry of Foreign Affairs & 2 & 6 \\
\hline 7 & Ministry of Tourism \& sports & 6 & 18 \\
\hline 8 & $\begin{array}{l}\text { Ministry of Social Development } \\
\text { and Human Security }\end{array}$ & 2 & 13 \\
\hline 9 & Ministry of Transport & 45 & 183 \\
\hline 10 & $\begin{array}{l}\text { Ministry of Natural Resources } \\
\text { and Environment }\end{array}$ & 7 & 23 \\
\hline 11 & Ministry of Energy & 11 & 55 \\
\hline 12 & Ministry of Commerce & 2 & 8 \\
\hline 13 & Ministry of Interior & 62 & 192 \\
\hline 14 & Ministry of Justice & 7 & 24 \\
\hline 15 & Ministry of Culture Thailand & 4 & 18 \\
\hline 16 & $\begin{array}{l}\text { Ministry of Science and } \\
\text { Technology }\end{array}$ & 15 & 62 \\
\hline 17 & Ministry of Education & 153 & 776 \\
\hline 18 & Ministry of Public Health & 117 & 443 \\
\hline 19 & Ministry of Industry & 12 & 37 \\
\hline 20 & The Prime Minister's Office & 11 & 38 \\
\hline 21 & Independent public agencies & 43 & 191 \\
\hline & & & \\
\hline
\end{tabular}

\subsection{Potential of energy saving by changing the significant equipments}

Although the agency of the designated government buildings have already implemented energy management system, the government has the idea to subsidize for changing the significant equipments. That is the way to reduce the energy consumption in the buildings rapidly.

Therefore, the number of the significant equipments (such as Fluorescent lamp, chiller, and boiler) has been collected. Then, the Potential of energy saving by changing the significant equipments and using the high efficiency equipments has been evaluated.

For Fluorescent lamp, in Thailand, most buildings usually installed the Fluorescent lamp T8 $(36 \mathrm{w})$. The total number of T8 is about 2 million lamps. In the case of changing T8 to LED (20w) which having the same luminous intensity, we can reduce energy consumption to 147,188,761 kwhr/year (about BHT 588 million per year) with the investment costs BHT 2,000 million.

For air conditioning unit (split type), this is the most equipment installing for air conditioning of every type of buildings in Thailand. In designated buildings of government agency, the total number 133,452 units of split type have been installed more than 10 years. In the case of changing to High efficiency equipment which having EER higher than 11.0, we can reduce energy consumption to 467,106,540 kwhr/year (about BHT 1,868 million per year) with the investment costs BHT 5,000 million. Table 5 shows potential of energy savings for various size of air conditioning unit.

Table 5. Potential of energy savings of air conditioning unit categorized by size

\begin{tabular}{|l|l|c|r|}
\hline No & \multicolumn{1}{|c|}{ Size (Btu/h) } & Number & $\begin{array}{c}\text { Energy saving } \\
\text { (kwh/year) }\end{array}$ \\
\hline 1 & $\leq 12,000$ & 13,528 & $19,916,359$ \\
\hline 2 & 13,000 & 7,932 & $14,213,539$ \\
\hline 3 & 15,000 & 3,622 & $6,951,479$ \\
\hline 4 & 18,000 & 18,889 & $43,688,097$ \\
\hline 5 & 24,000 & 18,064 & $57,752,346$ \\
\hline 6 & 30,000 & 27,298 & $102,813,384$ \\
\hline 7 & 36,000 & 25,704 & $117,473,344$ \\
\hline 8 & 40,000 & 8,561 & $44,560,704$ \\
\hline 9 & 44,000 & 2,953 & $17,267,279$ \\
\hline 10 & 48,000 & 5,751 & $35,094,669$ \\
\hline 11 & 50,000 & 1,150 & $7,375,340$ \\
\hline
\end{tabular}

For chiller, the equipment has been installed in the buildings usually more than 15 years with total number of 310 units and having the cooling capacity 73,000 Ton. In the case of changing to High efficiency chiller which having COP lower than $0.6 \mathrm{kw} /$ Ton, we can reduce energy consumption to 238,634,704 kwhr/year (about BHT 1,454 million baht per year) with the investment costs BHT 1,500 million.

For boiler, this equipment is used for disinfection and sterilization of medical equipments in the hospital under control of Ministry of Public Health. Total number of 
boilers that have been installed more than 15 years is 77 units (thermal efficiency lower than $70 \%$ ). In the case of changing to High efficiency boiler which having thermal efficiency higher than $85 \%$, we can reduce energy consumption to 51,563,636 $\mathrm{MJ} /$ year (about BHT 37 million per year) with the investment costs BHT 250 million as shown in Table 6.

Table 6. Potential of energy saving by changing equipments.

\begin{tabular}{|l|l|c|}
\hline No & \multicolumn{1}{|c|}{ Government agency } & $\begin{array}{c}\text { Saving } \\
\text { ktoe /year }\end{array}$ \\
\hline 1 & LED lamp & 12.54 \\
\hline 2 & High efficiency air conditioning (split type) & 39.80 \\
\hline 3 & High efficiency chiller & 20.33 \\
\hline 4 & High efficiency boiler & 1.22 \\
\hline & total & 73.89 \\
\hline
\end{tabular}

\subsection{Energy savings}

There were 839 designated buildings involved in the project. The total energy consumption was 438,940 tons of oil equivalent per year (toe/year) of which the total consumption consists of 4,846,583,072 $\mathrm{kWh}$ of electricity and 1096,618,329 MJ of thermal energy. During the project period, there were many energy conservation measures recommended by energy experts have been implemented. Energy savings are 169,124,575 kWh of electricity and $86,834,887 \mathrm{MJ}$ of thermal energy. This savings is about $3 \%$ of energy consumptions of buildings.

\subsection{Altitudes and Suggestions}

Some agencies did not complete the requirements of energy management system according to the law due to problems during procedures. Staff also did not realize the importance of a person responsible for energy and energy conservation activities because of lack of support from administrators and budget. Therefore, administrator should focus on energy management system in their organization. The importance and knowledge of energy conservation should be instilled to staff at all levels.

Government buildings suggested to DEDE including many interesting issues for carrying out the project further in future as follows:

1. The budget of buildings for changing significant devices such as air conditioning units, electrical and lighting is very limited. Therefore, DEDE should establish a support project for energy saving equipment modification to the building sector.

2. To motivate and encourage the implementation of energy conservation building sector, DEDE should provide for national competitions and awards for outstanding public buildings participating.

3. DEDE should provide a person for responsible energy (PRE) for buildings directly. The provincial energy officials have to facilitate coordination and take part in the operations of the government building and shipping information via email directly to PRE of the building.

4. DEDE should provide a team of experts to advise constantly not only just during the preparation of energy management, but continue long-term.
5. DEDE should focus on the promotion of energy conservation thoroughly. This includes practical and pragmatic. Also, DEDE should provide a meeting or training specifically for executives of government buildings who have primacy.

\subsection{Suggestions for the building sector}

The results of the implementation of the program found that some government buildings cannot be fully implemented energy conservation. This partly stems from the internal administration, the attitude of the staff and administrators of public buildings. This conclusion is as follows.

1. Government buildings should have a meter installed in each of the separate entities to be able to monitor and track energy consumption in detail.

2. Large public Building including many departments is still lacking in operation such as gathering data in preparing the report, and the establishment of energy conservation measures. Therefore, the chief executive of the government building should define policy and the annual budget for the implementation of energy management in particular to reduce restrictions on operations.

\section{Conclusion}

The continuous project of promotion and conducting the energy conservation regulation and supervision of designated government buildings in 2015 has been evaluated in this paper. The development of energy management and energy conservation measures of 839 designated government buildings were evaluated using questionnaires, direct interview and the data from the report of energy management work plan and target. It can be concluded that buildings are able to implement energy management system with experiences and consistency. This influences to energy savings of buildings and energy conservation activities occurred in the period of project. The according result of potential of energy saving by changing to use high efficiency equipment is about 73.89 ktoe/year. Finally, energy savings occurred in period of project is about 438.94 ktoe/year. For the attitude of buildings, It can be seen that most of designated government buildings were able to provide the requirements of energy management system according to the law.

\section{Acknowledgment}

The paper is based upon work supported by Department of Alternative Energy Development and Efficiency (DEDE) of Thailand.

\section{References}

1. Energy Conservation Promotion Act (No. 2) B.E.2550, Kingdom of thailand 
2. The Department of Alternative Energy Development and Efficiency, Enhancing the Promotion of Energy Management in Designated Factories and Designated Buildings, Final Report, (2009)

3. Energy Development and Promotion Act B.E. 2535 (1992), Kingdom of Thailand

4. Ministerial regulation B.E. 2539 (1996), Ministry of Energy, Kingdom of Thailand

5. C. Asavatesanupap, M. Santikunaporn, and P. Wangsakarn, "Energy conservation through valueengineering for SMEs in Thailand", The 5th European Conference Economics and Management of Energy in Industry Proceedings, April 2009, Vilamoura, Portugal

6. P.Wangskarn, and M.Sasananan, "Comparison of performance-based VS cost-based energy saving project", 2nd WSEAS/IASME International Conference on Energy Planning, Energy Saving, Environmental Education (EPESE’08) Corfu, Greece, October 26-28, (2008)

7. Thammasat University, The final report of promotion and conducting the energy conservation regulation and supervision of designated government buildings Project in 2015 